\title{
Reducing salt intake to prevent hypertension and cardiovascular disease
}

\author{
Feng J. He, ${ }^{1}$ Norm R. C. Campbell, ${ }^{2}$ and Graham A. MacGregor ${ }^{1}$
}

Suggested citation He FJ, Campbell NRC, MacGregor GA. Reducing salt intake to prevent hypertension and cardiovascular disease. Rev Panam Salud Publica. 2012;32(4):293-300.

\begin{abstract}
There is compelling evidence that dietary salt intake is the major cause of raised blood pressure $(B P)$ and that a reduction in salt intake from the current level of $\approx 9-12 \mathrm{~g} /$ day in most countries to the recommended level of $<5 \mathrm{~g} /$ day lowers BP. A further reduction to 3-4 g/day has a greater effect and there needs to be ongoing consideration of lower targets for population salt intake. Cohort studies and outcome trials have demonstrated that a lower salt intake is related to a reduced risk of cardiovascular disease. Salt reduction is one of the most costeffective measures to improve public health worldwide. In the Americas, a salt intake of $>9 \mathrm{~g} /$ day is highly prevalent. Sources of salt in the diet vary hugely among countries; in developed countries, $75 \%$ of salt comes from processed foods, whereas in developing countries such as parts of Brazil, $70 \%$ comes from salt added during cooking or at the table. To reduce population salt intake, the food industry needs to implement a gradual and sustained reduction in the amount of salt added to foods in developed countries. In developing countries, a public health campaign plays a more important role in encouraging consumers to use less salt coupled with widespread replacement of salt with substitutes that are low in sodium and high in potassium. Numerous countries in the Americas have started salt reduction programs. The challenge now is to engage other countries. A reduction in population salt intake will result in a major improvement in public health along with major health-related cost savings.
\end{abstract}

Key words Sodium chloride, dietary; blood pressure; hypertension; cardiovascular diseases; Americas.

Raised blood pressure (BP) is the leading cause of death and the second leading cause of disability worldwide, accounting for 7.6 million premature deaths (about $14 \%$ of the global total) and 92 million disability-adjusted life years $(6 \%$ of the global total) (1). Worldwide, approximately 1 billion individuals (a quarter of the adult population) had high BP (> 140/90 mmHg) in 2000 and the number is predicted to increase to about 1.5

\footnotetext{
1 Wolfson Institute of Preventive Medicine, Barts and The London School of Medicine and Dentistry, Queen Mary University of London, London, United Kingdom. Send correspondence to: Feng He, f.he@qmul.ac.uk

2 Libin Cardiovascular Institute of Alberta, University of Calgary, Calgary, Alberta, Canada.
}

billion by 2025 (2). In the Americas, onefifth to one-third of adults has high BP. In Latin America and the Caribbean, the rates range from around $20 \%$ of adults in Panama to more than $40 \%$ in St. Lucia and they are among the highest in the world (3). The damage caused by raised $\mathrm{BP}$ is mainly through its effects on cardiovascular disease (CVD) (strokes, heart attacks, heart failure) and kidney disease. Worldwide raised $\mathrm{BP}$ is responsible for $62 \%$ of strokes and $49 \%$ of coronary heart disease (4). The costs of raised BP are estimated at $5 \%-15 \%$ of the gross domestic product in high-income countries and 2.5\%-8\% in Latin America and the Caribbean (3). Stroke mortality rates, the key outcome of increased BP, are very high in Latin America and the Caribbean, with annual rates up to 77.5 deaths per 100000 women in St. Lucia (5).

There is compelling evidence that dietary salt intake is the major cause of raised BP. The salt intake in most countries is between 9 and $12 \mathrm{~g} /$ day (6). Where assessed in Latin America and the Caribbean after 2000, salt intake exceeds $9 \mathrm{~g} /$ day (7). This level of salt intake is about 40 times higher than the amount human ancestors ate during several million years of evolution. Such a large increase in salt intake is relatively recent in evolutionary terms. Excreting these large amounts of salt through the kidneys pres- 
ents a major challenge to physiological systems. The consequence is a gradual rise in $\mathrm{BP}(8,9)$ and an increase in the risk of CVD and renal disease. This paper provides a brief update on the evidence relating salt intake to BP and CVD. It also provides a brief update on salt reduction programs being carried out in several countries, particularly in the Americas.

\section{SALT AND SODIUM}

In the United States of America and Canada, the term "sodium" is used, whereas in most other countries "salt" is used. The two terms are often used synonymously. However, on a weight basis, salt comprises $40 \%$ sodium and $60 \%$ chloride. The conversion of different units for sodium and salt is as follows: $1 \mathrm{~g}$ of sodium $=2.5 \mathrm{~g}$ of salt, $1 \mathrm{mmol}$ of sodium $=23 \mathrm{mg}$ of sodium, $1 \mathrm{~g}$ of salt $=0.4 \mathrm{~g}$ of sodium, and $1 \mathrm{~g}$ of salt $=17 \mathrm{mmol}$ of sodium. Salt is the major source of sodium in the diet $(\approx 90 \%)$. This article uses the term "salt" unless otherwise specified.

\section{EVIDENCE ON SALT AND BP}

The evidence that relates salt intake to BP comes from various types of studies, including epidemiologic (10), migration (11), population-based intervention (12), genetic (13), and animal studies (14) as well as treatment trials (15). The most relevant animal studies are those in chimpanzees $(98.8 \%$ genetic homology with humans), which demonstrated progressive and large increases in BP when salt intake increased from $0.5 \mathrm{~g} /$ day, which is close to humans' evolutionary intake, to $10-15 \mathrm{~g} /$ day, which is similar to current salt intakes (14). In chimpanzees who had been on a high salt intake, a modest reduction in salt intake lowered $\mathrm{BP}$ and the fall in $\mathrm{BP}$ was as large as or larger for salt intakes at or below the recommended levels of 5-6 g/day (16). Epidemiologic studies in humans have shown that salt intake is directly related to $\mathrm{BP}$, and communities with a higher salt intake have a higher mean population BP. Additionally, the current high salt intake is largely responsible for the rise in BP with age seen in most countries of the world (9).

Population-based intervention studies have shown that when salt intake is decreased, there is a reduction in population $\operatorname{BP}(12,17)$. For example, a study in two similar villages in Portugal (12) achieved a difference of $\approx 50 \%$ in salt intake between the two villages (i.e., intervention versus control) over 2 years, and this change resulted in a difference in $\mathrm{BP}$ of 13/6 mmHg. Many randomized trials have consistently demonstrated that a modest reduction in salt intake lowers BP. The BP-lowering effect is shown in both hypertensive and normotensive individuals, in all age groups, and in all ethnic groups, although there are variations in the magnitude of the falls in BP with salt reduction $(18,19)$.

\section{HOW FAR SHOULD SALT INTAKE BE REDUCED?}

A number of studies in animals have shown a clear dose-response relationship between salt intake and BP $(14,20)$. For example, the studies in chimpanzees referred to earlier demonstrated that, within a range of $0.5-15 \mathrm{~g} /$ day, the higher the salt intake, the higher the BP (14). Observational epidemiologic studies suggested that such a dose-response relationship also exists in humans, with salt intake ranging from $0.01-14 \mathrm{~g} /$ day (9). However, it is extremely difficult to carry out a randomized trial to test this relationship as it is impossible to keep individuals on a very low salt diet in the long term because of the widespread presence of salt in nearly all processed, restaurant, canteen, and fast foods. Nevertheless, two well-controlled trials have studied three salt intakes $(18,21)$. One was the randomized double-blind crossover study in 20 individuals with untreated essential hypertension, in which salt intake was reduced from 11.2 to 6.4 to $2.9 \mathrm{~g}$ / day, each amount for one month (21). BP was $163 / 100 \mathrm{mmHg}$ with a salt intake of $11.2 \mathrm{~g} /$ day, and it declined to $155 / 95 \mathrm{mmHg}$ when salt intake was decreased to $6.4 \mathrm{~g} /$ day (i.e., a decrease of $8 / 5 \mathrm{mmHg}$ ). BP fell further to $147 / 91$ $\mathrm{mmHg}$ when salt intake was decreased to $2.9 \mathrm{~g}$ /day (i.e., a further fall of $8 / 4$ $\mathrm{mmHg}$ ). After the trial was completed, individuals continued on the lowest salt intake. Among the 20 participants, 19 were followed up for 1 year. In 16 individuals, BP remained controlled without any antihypertensive medication and the average $\mathrm{BP}$ was $142 / 87 \mathrm{mmHg}$ with a salt intake of $3.2 \mathrm{~g} /$ day (21). The Dietary Approaches to Stop Hypertension (DASH)-Sodium trial (18), which studied 412 individuals with normal or mildly elevated BP, also demonstrated a clear dose-response relationship when salt intake was decreased from 8 to 6 to $4 \mathrm{~g} /$ day. The fall in BP was greater at a lower level of salt intake from 6 to 4 $\mathrm{g} /$ day compared with that from 8 to 6 g/day. The dose-response relationship was observed on the normal American diet and on the DASH diet, which is rich in fruits, vegetables, and low-fat dairy products (Figure 1) (18). Individuals on the DASH diet, with the lowest level of salt intake, had the lowest BP.

From the evidence above, it is clear that the current recommendations to reduce salt intake from 9-12 g/day in most countries of the world to the level of $<5 \mathrm{~g}$ /day as recommended by the World Health Organization (WHO) will have a major effect on BP but are not ideal. A further reduction to $3 \mathrm{~g} /$ day will have a much greater effect on $\mathrm{BP}$, and there needs to be ongoing consideration of lower targets for population salt intake. Recently, the United Kingdom's government health advisory agency, the National Institute for Health and Clinical Excellence, recommended a reduction in the population's salt consumption to $3 \mathrm{~g} /$ day by 2025 (22). In the United States, it is recommended that sodium intake be reduced to $<2300$ $\mathrm{mg} /$ day (salt intake of $5.75 \mathrm{~g} /$ day) for adults, with a further reduction to 1500 $\mathrm{mg} /$ day (salt intake of $3.75 \mathrm{~g} /$ day) for about half the population, including African Americans; all adults aged 51 years or older; and individuals with hypertension, diabetes, or chronic kidney disease (23). In Canada, the Sodium Working Group recommends adequate intake, which is 1500 $\mathrm{mg} /$ day (salt intake of $3.75 \mathrm{~g} /$ day) for persons aged 9-50 years and less for those younger than 9 or older than 50 years (24).

\section{EVIDENCE ON SALT AND CARDIOVASCULAR DISEASE}

There is much evidence that raised BP throughout its range, starting at 115/75 $\mathrm{mmHg}$, is a major cause of CVD (25). A modest reduction in salt intake lowers $\mathrm{BP}$ and therefore would reduce the risk of CVD. Based on the fall in BP from a meta-analysis of randomized salt reduction trials (26), it was estimated that a reduction in salt intake of $6 \mathrm{~g} /$ day would reduce strokes by $24 \%$ and coronary heart disease by $18 \%$. This reduction would prevent $\approx 35000$ deaths due to stroke and coronary heart disease each year in the United Kingdom (15) and $\approx 2.5$ million deaths worldwide. 
FIGURE 1. Changes in blood pressure and 24-hour urinary sodium excretion with reduction in salt intake in all participants (hypertensives: $n=169$, normotensives: $n=243$ ) on normal American diet (control) and on Dietary Approaches to Stop Hypertension (DASH) diet

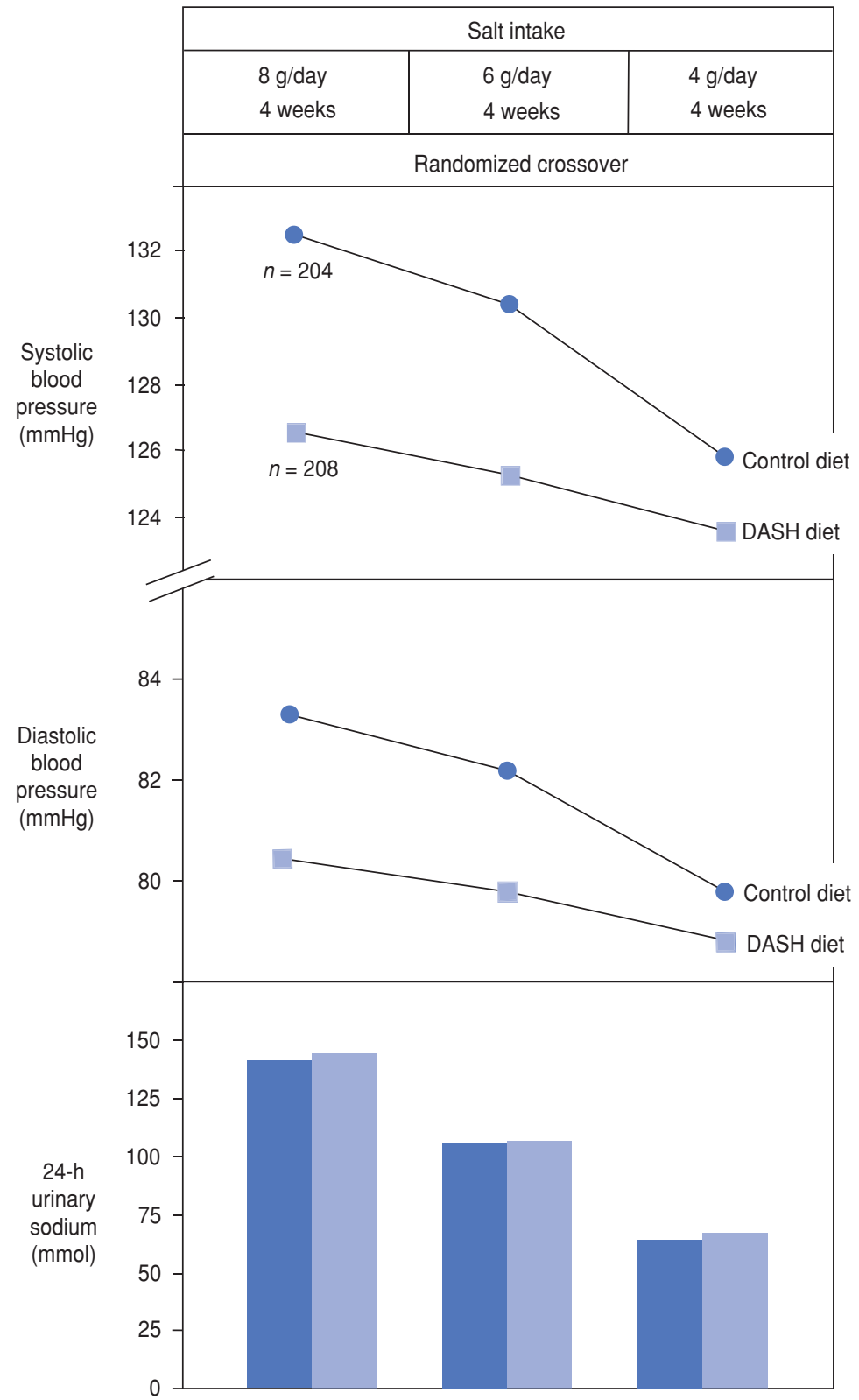

Data from Sacks et al. (18).

Both prospective cohort studies and outcome trials have shown that a lower salt intake is related to a reduced risk of CVD $(27,28)$. Two recent papers in the Journal of the American Medical Association, however, claimed that a lower salt intake was associated with higher cardiovascular mortality (29) or that a J-shaped association existed between salt intake and cardiovascular risk (30). Those two papers have many methodologic flaws-for example, a measurement error in assessing daily salt intake, confounding factors not controlled for, and reverse causality (i.e., low salt intake is the result rather than the cause of participants' illness) (31, 32). Hence, results from those studies should not be used to reverse or derail recommendations for population-wide salt reduction. A meta-analysis of 12 cohort studies showed that an increase of $5 \mathrm{~g} /$ day in salt intake was associated with a $23 \%$ increase in the risk of stroke and a $17 \%$ increase in the risk of CVD (Figure 2) (27).
Evidence from outcome trials of longterm salt reduction is very limited because of the innate difficulty in conducting such trials. A recent meta-analysis of seven randomized trials by Taylor et al., published simultaneously in The Cochrane Library (33) and the American Journal of Hypertension (34), did not find statistically significant effects of reduced salt consumption on CVD but had point estimates that favored a $3 \%$ and a $33 \%$ relative risk reduction in total mortality in hypertensive and normotensive people, respectively. The meta-analysis similarly had point estimates of reduced cardiovascular morbidity of $16 \%$ and $29 \%$ in hypertensive and normotensive people, respectively, that were not statistically significant.

Some weaknesses in the meta-analysis are worth considering. Among the seven trials included in the meta-analysis, one on severe heart failure (35) should not have been included as the subjects were severely salt and water depleted because of a protocol that included water restriction and mandatory extremely high doses of a diuretic (furosemide at 250 $500 \mathrm{mg} /$ day) that exceed many clinical recommendations (35). Additionally, the findings in patients with severe heart failure on multiple drug treatments are not generalizable to the general population. In the remaining six trials, there is a reduction in all clinical outcomes (allcause mortality, cardiovascular mortality, and cardiovascular events), although none of them is statistically significant. The nonsignificant findings are most likely due to a lack of statistical power, particularly as Taylor et al. analyzed the trials for hypertensive and normotensive participants separately. A reanalysis of the data by combining hypertensive and normotensive participants shows a significant $(20 \%)$ reduction in cardiovascular events $(P<0.05)$ (Figure 3$)$ and a nonsignificant $(5 \%-7 \%)$ reduction in allcause mortality, with a small reduction in salt intake of 2.0-2.3 g/day (36). These results add to the evidence that salt reduction has a major impact on reducing strokes, heart attacks, and heart failure.

\section{IS THERE ANY ADVERSE EFFECT OF SALT REDUCTION?}

It has been shown that, with an acute and large reduction in salt intake-for example, from 20 to $<1 \mathrm{~g} /$ day for a few days-there is a decrease in plasma 
FIGURE 2. Relative risk of stroke and total cardiovascular disease associated with an increased salt intake of $5 \mathrm{~g} /$ day in a meta-analysis of cohort studies

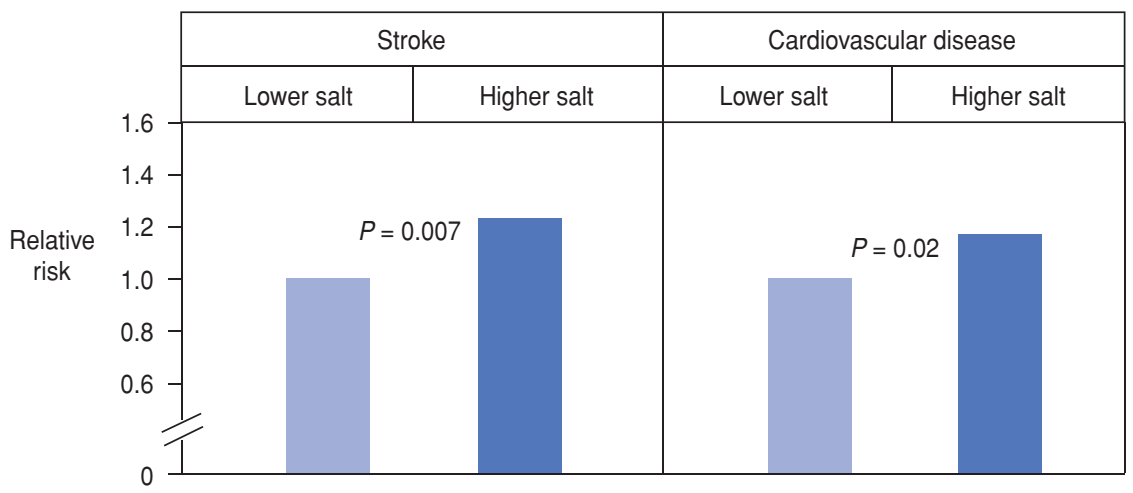

Data from Strazzullo et al. (27).

FIGURE 3. Cardiovascular disease (CVD) events at longest follow-up (duration varied between 7 months and 11.5 years) in a meta-analysis of randomized salt reduction trials using fixed-effect model with normotensives and hypertensives combined

\begin{tabular}{|c|c|c|c|c|c|c|c|}
\hline \multirow[b]{2}{*}{ Study } & \multicolumn{2}{|c|}{ Reduced-salt } & \multicolumn{2}{|c|}{ Control } & \multirow[b]{2}{*}{ Relative risk $(95 \% \mathrm{Cl})$} & & \\
\hline & Events & Total & Events & Total & & \multicolumn{2}{|c|}{ Relative risk of CVD events $(95 \% \mathrm{Cl})$} \\
\hline TOHP I & 17 & 321 & 32 & 311 & $0.51(0.29,0.91)$ & & \\
\hline TOHP ॥ & 71 & 938 & 80 & 935 & $0.88(0.65,1.20)$ & & \\
\hline Morgan & 6 & 34 & 5 & 33 & $1.16(0.39,3.45)$ & & \\
\hline TONE & 36 & 322 & 46 & 331 & $0.80(0.53,1.21)$ & & \\
\hline Total & 130 & 1615 & 163 & 1610 & $0.80(0.64,0.99)$ & + & + \\
\hline \multicolumn{6}{|c|}{$\begin{array}{l}\text { Heterogeneity: } \mathrm{Chi}^{2}=3.20, \mathrm{df}=3(P=0.36) ; /^{2}=6 \% \\
\text { Test for overall effect: } Z=2.02(P=0.04)\end{array}$} & $\begin{array}{l}0.1 \\
\text { Favours reduced-salt }\end{array}$ & $\begin{array}{l}10 \\
\text { Favours control }\end{array}$ \\
\hline \multicolumn{8}{|c|}{$\begin{array}{l}\text { Cl: confidence interval; TOHP I: Trial of Hypertension Prevention, phase 1; TOHP II: Trial of Hypertension Prevention, phase } \\
\text { 2; TONE: Trial of Nonpharmacologic Interventions in Elderly; df: degrees of freedom. } \\
\text { Reprinted from The Lancet, Vol. } 378 \text { (9789), He FJ, MacGregor GA, Salt reduction lowers cardiovascular risk: meta-analysis } \\
\text { of outcome trials, pp. 380-2, with permission from Elsevier. }\end{array}$} \\
\hline
\end{tabular}

volume and, thereby, a small increase in the concentration of plasma lipids. However, such a large change in salt intake is irrelevant to the current public health recommendation for population salt intake, which is a modest reduction in salt intake for a long time. With a longer-term modest salt intake, there is no significant change in cholesterol, low-density lipoprotein, high-density lipoprotein, or triglycerides (26). In a recent meta-analysis by Graudal et al. (37), a subgroup analysis that included trials with a duration of at least 4 weeks confirmed no significant change in lipids.

When salt intake is reduced, there is a physiological stimulation of the renin-angiotensin system and the sympathetic nervous system. These compensatory responses are bigger with sudden and large decreases in salt intake and much smaller or minimal with a modest reduction in salt intake over a more prolonged time. A meta-analysis of randomized trials of modest salt reduction with a duration of 1 month or longer showed that there was only a small increase in plasma renin activity and aldosterone (26). A study by Beckmann et al. demonstrated that a modest reduction in salt intake, along with a reduction in body weight and saturated fat intake for 1 year, significantly reduced arterial plasma norepinephrine and epinephrine in hypertensive individuals (38).

Salt reduction lowers BP by a mechanism similar to that of thiazide diuretics. Both stimulate the renin-angiotensin system and, in the short term, the sympathetic nervous system. However, outcome trials have demonstrated that long-term treatment with thiazide diuretics significantly reduced cardiovascular morbidity and mortality in hypertensive individuals (39).

\section{SALT REDUCTION IS A VERY COST-EFFECTIVE PUBLIC HEALTH POLICY}

Several studies have shown that a reduction in salt intake is one of the most cost-effective interventions to reduce CVD in both developed and developing countries (40-46). For instance, a study in the United States showed that a modest reduction in salt intake of only $10 \%$, which could be easily achieved, as demonstrated in the United Kingdom (47), would prevent hundreds of thousands of strokes and heart attacks over the lifetimes of adults aged $40-85$ years who are alive today and could save more than $\$ 32$ billion in medical expenses in the United States alone (46). A larger decrease in salt intake would result in a larger health improvement and greater cost savings. A reduction of $3 \mathrm{~g} /$ day would save 194000 to 392000 quality-adjusted life years and $\$ 10$ billion in health care costs annually (44). A study in Canada estimated that a reduction in salt intake of $4.6 \mathrm{~g} /$ day could save $\approx \$ 430$ million per year on drugs, physician visits, and laboratory testing directly related to hypertension (41). The salt reduction campaigns in the United Kingdom, which started in 2003-2004, have been successful and the average salt intake, as measured by 24hour urinary sodium, fell from 9.5 to $8.1 \mathrm{~g} /$ day by 2011 (47). It was estimated that the salt reduction campaigns in the United Kingdom, which cost just $£ 15$ million, led to $\approx 9000$ fewer CVD deaths per year, saving the country's economy more than $£ 1.5$ billion per annum (48).

A paper in the Lancet assessed the effects and costs of strategies to reduce salt intake and control tobacco use for 23 lowand middle-income countries, which account for $80 \%$ of chronic disease burden in the developing world (42). The results showed that, over 10 years (2006-2015), a $15 \%$ reduction in mean population salt intake could avert 8.5 million CVD deaths and a $20 \%$ reduction in smoking prevalence could avert 3.1 million CVD deaths. The modest reduction in salt intake could be achieved by a voluntary reduction in the salt content of processed foods and condiments by manufacturers combined with a sustained mass media campaign aimed at encouraging dietary change in households and communities. The costs for implementing such a strategy were estimated to be US $\$ 0.09$ per person per year (42). The cost for tobacco 
control, including price and nonprice measures, was US\$0.26 per person per year (42). These figures clearly suggest that a reduction in salt intake is more or at the very least just as cost-effective as tobacco control in terms of reducing CVD on its own, the leading cause of death and disability worldwide. A more recent analysis from Argentina showed that lowering salt intake in the population through reducing the amount of salt in bread was cost saving (49).

\section{WORLDWIDE ACTION TO REDUCE POPULATION SALT INTAKE}

In most developed countries, $\approx 80 \%$ of salt consumed is added to foods at the manufacturing stage (50), and consumers have no say over how much salt is added. Therefore, to reduce population salt intake, it is imperative that the food industry make a gradual and sustained decrease in the amount of salt they add to all foods. Several countries have successfully carried out salt reduction programs and salt intake has fallen. For example, Finland initiated a systematic approach to reduce salt intake in the late 1970s through mass media campaigns, cooperation with the food industry, and implementation of salt labeling legislation (51-53). This approach led to a significant reduction in the average salt intake of the Finnish population $(51,53)$ from $\approx 14 \mathrm{~g} /$ day in 1972 to $<9 \mathrm{~g} /$ day in 2002 (51). The reduction in salt intake was accompanied by a decline in both systolic and diastolic BP of $>10 \mathrm{mmHg}$ and a decrease of $75 \%-80 \%$ in mortality from stroke and coronary heart disease (51). Although these results were attributable to several factors, reduced salt intake played a major role, particularly in the fall in BP as both body mass index and alcohol consumption had increased during that period.

The United Kingdom has successfully developed a program of voluntary salt reduction in collaboration with the food industry. In 1996, 22 experts on salt and $\mathrm{BP}$ set up an action group: Consensus Action on Salt and Health (CASH) (54). CASH has waged a high-profile campaign to persuade food manufacturers and suppliers to universally and gradually reduce the salt content of processed foods, educate the public in becoming more salt aware in terms of understanding the impact of salt on their health, and translate the evidence into public health policy. CASH persuaded the Department of Health in the United Kingdom to endorse the recommendation of the Committee on Medical Aspects of Food and Nutrition Policy on salt and also ensured that the Food Standards Agency took on the task of reducing salt intake. In 2003, CASH developed a nationwide strategy with an aim of implementing a stepwise reduction in the amount of salt added to foods $-10 \%-20 \%$ reduction repeated at 1 - to 2-year intervals $(8,54)$. In 2006, the Food Standards Agency set target levels of salt for 80 food categories that the food industry needed to achieve within a certain time period. These targets were revised down in 2009 to ensure that salt intake will reach the target of $6 \mathrm{~g} /$ day by 2014 (55).

After the success of the campaign group CASH in the United Kingdom, World Action on Salt and Health (WASH) was established in 2005 (56). The aim of WASH is to set up similar groups modeled on CASH suited to each individual country to reduce salt intake with an appropriate strategy relevant to the needs of that particular country and to stimulate actions from the government, the food industry, the media, and the public. WASH is supported by $>450$ members from 85 countries.

In 2009, WASH conducted a survey of $>260$ branded products (e.g., KFC, McDonald's, Kellogg's, Nestlé, Burger King, Subway) in different countries and revealed huge variations in salt content in global brands unrelated to local traditional taste preferences. No product surveyed had the same salt content around the world and some displayed huge differences from one country to another. For instance, Kellogg's All-Bran contained $2.15 \mathrm{~g}$ of salt per $100 \mathrm{~g}$ in Canada, but only $0.65 \mathrm{~g}$ of salt per $100 \mathrm{~g}$ just over the border in the United States, less than a third of the Canadian level (56). This finding illustrates once again how easy it would be for the food industry to reduce the amount of salt they add to foods, particularly as they can do it straightaway to their branded products. Pressure from campaigns has resulted in several large multinational manufacturers pledging to reduce the amount of salt added to foods across the world.

In the United States, there has been consistent advice to reduce salt intake to $<6$ g/day since the 1980s. However, little action was taken until recently. In 2005, in a petition to the Food and Drug Admin- istration (FDA), the Center for Science in the Public Interest called for tougher regulations on salt (57). In 2007, the American Medical Association published a report calling for a major reduction in the salt content of processed and restaurant foods (58). The FDA has been urged to terminate the rule that allows salt and its component sodium to be treated as "generally recognized as safe" $(57,58)$. In November 2008, Michael Bloomberg, the Mayor of New York City, announced his plan to cut salt levels in processed foods by $20 \%$ over 5 years. In January 2010, the National Salt Reduction Initiative, a New York City-led partnership of $>40$ cities, states, and national health organizations, unveiled its proposed targets to guide a voluntary reduction of salt levels in packaged and restaurant foods with the aim of reducing Americans' salt intake by $20 \%$ over 5 years and by $40 \%$ over 10 years (59). To achieve these reductions, the salt content of processed and packaged foods needs to decline by $25 \%$ in 5 years and by $50 \%$ in 10 years. Similar to the strategy in the United Kingdom, the National Salt Reduction Initiative in the United States has developed voluntary 2- and 4-year interim targets for cutting salt levels in restaurant and packaged foods (59).

In April 2010, the Institute of Medicine released a report on strategies to reduce sodium intake in the United States (23). The report recommends setting mandatory national standards for the salt levels that food manufacturers, restaurants, and food service companies can add to their products in the United States and that all the relevant health agencies should be involved in achieving this goal. The FDA's role, as envisioned in the report, will be to set the new standards, which can be phased in gradually, allowing tastes to adjust over time, although no timescale has been given. After publication of the Institute of Medicine report, 16 food companies in the United States, including food manufacturers Kraft Foods and Heinz, pledged to cut the amount of salt in some of their products.

In Canada, after advocacy by nongovernmental health care organizations and based on the recommendations of an intersectoral sodium working group, the federal and provincial governments agreed to an interim target of $5.75 \mathrm{~g}$ of salt/day by $2016(24,60)$. The governments are providing guidance to in- 
dustry and are planning an educational program, but unfortunately the federal government's policies do not appear to be substantive enough to have a significant impact on population salt consumption.

In February 2010, the Pan American Health Organization-WHO Regional Expert Group on Cardiovascular Disease Prevention through Dietary Salt Reduction (3) produced a policy statement outlining the recommendations for a population-based approach to reduce dietary salt intake in the Americas. The policy statement provides countries with a roadmap for concerted actions by governments, nongovernmental organizations, and the food industry. The goal is a gradual and sustained drop in dietary salt intake to reach national targets or the target recommended by WHO of $<5$ g/day by 2020 . Several additional countries in the Americas have taken up the challenge and started salt reduction programs (3). Notably, Argentina, Brazil, Chile, Costa Rica, Cuba, Guatemala, Mexico, Suriname, and Uruguay have specific plans or ongoing programs to lower dietary salt intake. Belize, Colombia, the Dominican Republic, Ecuador, El Salvador, Honduras, Nicaragua, Panama, and Paraguay have plans to introduce salt reduction programs, and several other countries have plans to lower dietary salt as a part of more global programs to reduce the level of chronic noncommunicable disease. Barbados is conducting baseline surveillance of dietary salt.

Several developing countries outside the Americas have launched national salt reduction initiatives. For example, in September 2011, South Africa set a target to reduce salt intake to $<5 \mathrm{~g} /$ day by 2020 (61). This reduction will be achieved by a public health campaign and by regulating the food industry.

In many developing countries, the major sources of salt consumption are additions during cooking and in sauces (e.g., soy sauce), spice mixes, seasonings, and pickles rather than prepackaged prepared foods (62). Public health campaigns are needed to encourage people to use less salt in their own food preparation. An ancillary approach is to replace salt with a mineral salt (i.e., low in sodium and high in potassium), which has been shown to lower blood pressure and reduce cardiovascular mortality $(63,64)$. It is important to note that, in developing countries, more processed foods are being consumed as diets are becoming westernized. The food industry in these countries is poorly regulated with very little or no food-content labeling, which makes informed eating almost impossible. Therefore, these countries need a combined policy of getting the public to use less salt at home and getting the food industry to reduce the amount of salt added to foods and to adopt a clear labeling system such as the signpost labeling system (65). At the same time, developing countries need to ensure that all imported food products are low in salt.

\section{CONCLUSIONS}

The totality of the evidence for a causal relationship between chronic high salt intake and elevated $\mathrm{BP}$ and CVD is robust. WHO has recommended salt reduction as one of the top three priority actions to tackle the global noncommunicable disease crisis. Several countries (e.g., Finland and the United Kingdom) have successfully carried out salt reduction programs and salt intake has fallen. Numerous countries in the Americas are following the lead of the United Kingdom and have launched national salt reduction initiatives. Since 2009, the momentum for population-level salt reduction has grown in that region, led by the Pan American Health Organization.

Reducing population salt intake requires action at all levels, including the government, the food industry, nongovernmental organizations, health professionals, and the public. A key to success is to set specific targets for salt content for all food categories with a clear time frame and monitoring program. Despite the fact that regulation and legislation are more effective than voluntary approaches, the complicated process of legislation in many countries would lead to severe delays in action. The best way to proceed is to start with a voluntary salt reduction policy while legislation is enacted. In view of the enormous benefits of salt reduction on public health, it would be negligent for any government not to take action now.

Acknowledgment. The authors thank Branka Legetic for kindly providing the epidemiologic data on salt intake, hypertension, and CVD in the Americas.

\section{REFERENCES}

1. Lawes CM, Vander Hoorn S, Rodgers A. Global burden of blood-pressure-related disease, 2001. Lancet. 2008;371:1513-8.

2. Kearney PM, Whelton M, Reynolds K, Muntner P, Whelton PK, He J. Global burden of hypertension: analysis of worldwide data. Lancet. 2005;365:217-23.

3. Pan American Health Organization-World Health Organization. Cardiovascular disease prevention through dietary salt reduction. Washington, D.C.: PAHO-WHO; 2011. Available from: http://new.paho.org/hq/index. php?option $=$ com_content\&task $=$ view $\&$ id $=20$ 15\&Itemid=1757 Accessed 21 May 2012.

4. World Health Organization. The world health report 2002: reducing risks, promoting healthy life. Geneva: WHO; 2002. Available from: www.who.int/whr/2002 Accessed 28 August 2012.

5. Pan American Health Organization. Noncommunicable disease project and health information and analysis project and sustainable development and environment area: noncommunicable diseases in the Americas: basic indicators 2011. Washington, D.C.: PAHO; 2011. Available from: http://new.paho.org/hq/ index.php?option $=$ com_content\&task $=$ view \&id $=1512 \&$ Itemid $=1663 \&$ lang $=$ en Accessed 3 June 2012.

6. Brown IJ, Tzoulaki I, Candeias V, Elliott P. Salt intakes around the world: implications for public health. Int J Epidemiol. 2009;38:791-813.

7. Legetic B, Campbell N. Reducing salt intake in the Americas: Pan American Health Orga- nization actions. J Health Commun. 2011;16 (Suppl 2):37-48.

8. He FJ, MacGregor GA. Reducing population salt intake worldwide: from evidence to implementation. Prog Cardiovasc Dis. 2010;52: 363-82.

9. Intersalt Cooperative Research Group. Intersalt: an international study of electrolyte excretion and blood pressure. Results for 24 hour urinary sodium and potassium excretion. BMJ. 1988;297:319-28.

10. Elliott P, Stamler J, Nichols R, Dyer AR, Stamler R, Kesteloot H, et al. Intersalt revisited: further analyses of 24 hour sodium excretion and blood pressure within and across populations. Intersalt Cooperative Research Group. BMJ. 1996;312:1249-53. 
11. Poulter NR, Khaw KT, Hopwood BE, Mugambi M, Peart WS, Rose G, et al. The Kenyan Luo migration study: observations on the initiation of a rise in blood pressure. BMJ. 1990;300:967-72.

12. Forte JG, Miguel JM, Miguel MJ, de Pádua F, Rose G. Salt and blood pressure: a community trial. J Hum Hypertens. 1989;3:179-84.

13. Lifton RP. Molecular genetics of human blood pressure variation. Science. 1996;272:676-80.

14. Denton D, Weisinger R, Mundy NI, Wickings EJ, Dixson A, Moisson P, et al. The effect of increased salt intake on blood pressure of chimpanzees. Nat Med. 1995;1:1009-16.

15. He FJ, MacGregor GA. How far should salt intake be reduced? Hypertension. 2003;42:1093-9.

16. Elliott P, Walker LL, Little MP, Blair-West JR, Shade RE, Lee DR, et al. Change in salt intake affects blood pressure of chimpanzees: implications for human populations. Circulation. 2007;116:1563-8

17. Tian HG, Guo ZY, Hu G, Yu SI, Sun W, Pietinen $P$, et al. Changes in sodium intake and blood pressure in a community-based intervention project in China. J Hum Hypertens. 1995;9:959-68.

18. Sacks FM, Svetkey LP, Vollmer WM, Appel LJ, Bray GA, Harsha D, et al. Effects on blood pressure of reduced dietary sodium and the Dietary Approaches to Stop Hypertension (DASH) diet. DASH-Sodium Collaborative Research Group. N Engl J Med. 2001;344:3-10.

19. He FJ, Markandu ND, Sagnella GA, MacGregor GA. Importance of the renin system in determining blood pressure fall with salt restriction in black and white hypertensives. Hypertension. 1998;32:820-4.

20. Dahl LK, Knudsen KD, Heine MA, Leitl GJ. Effects of chronic excess salt ingestion. Modification of experimental hypertension in the rat by variations in the diet. Circ Res. 1968;22:11-8.

21. MacGregor GA, Markandu ND, Sagnella GA, Singer DR, Cappuccio FP. Double-blind study of three sodium intakes and long-term effects of sodium restriction in essential hypertension. Lancet. 1989;334:1244-7.

22. National Institute for Health and Clinical Excellence. Guidance on the prevention of cardiovascular disease at the population level. London: NICE; 2010. Available from: http:// guidance.nice.org.uk/PH25 Accessed 14 July 2010.

23. Institute of Medicine. Strategies to reduce sodium intake in the United States. Washington, D.C.: IOM; 2010. Available from: www.iom. edu/Reports / 2010/Strategies-to-ReduceSodium-Intake-in-the-United-States.aspx Accessed 28 May 2010

24. Sodium Working Group. Sodium reduction strategy for Canada. Ottawa: Health Canada; 2010. Available from: http://publications. gc.ca/collections/collection_2010/sc-hc/ H164-121-2010-eng.pdf Accessed 8 June 2012.

25. Lewington $S$, Clarke R, Qizilbash N, Peto R, Collins R. Age-specific relevance of usual blood pressure to vascular mortality: a metaanalysis of individual data for one million adults in 61 prospective studies. Lancet. 2002;360:1903-13.

26. He FJ, MacGregor GA. Effect of modest salt reduction on blood pressure: a meta-analysis of randomized trials. Implications for public health. J Hum Hypertens. 2002;16:761-70.
27. Strazzullo P, D Elia L, Kandala NB, Cappuccio FP. Salt intake, stroke, and cardiovascular disease: meta-analysis of prospective studies. BMJ. 2009;339:b4567.

28. Cook NR, Cutler JA, Obarzanek E, Buring JE, Rexrode KM, Kumanyika SK, et al. Long term effects of dietary sodium reduction on cardiovascular disease outcomes: observational follow-up of the trials of hypertension prevention (TOHP). BMJ. 2007;334:885-8.

29. Stolarz-Skrzypek K, Kuznetsova T, Thijs L, Tikhonoff V, Seidlerová J, Richart T, et al. Fatal and nonfatal outcomes, incidence of hypertension, and blood pressure changes in relation to urinary sodium excretion. JAMA. 2011;305:1777-85.

30. O'Donnell MJ, Yusuf S, Mente A, Gao P Mann JF, Teo K, et al. Urinary sodium and potassium excretion and risk of cardiovascular events. JAMA. 2011;306:2229-38.

31. He FJ, Appel LJ, Cappuccio FP, de Wardener HE, MacGregor GA. Does reducing salt intake increase cardiovascular mortality? Kidney Int. 2011;80:696-8.

32. He FJ, Macgregor GA. Cardiovascular disease: salt and cardiovascular risk. Nat Rev Nephrol. 2012;8:134-6.

33. Taylor RS, Ashton KE, Moxham T, Hooper L, Ebrahim S. Reduced dietary salt for the prevention of cardiovascular disease. Cochrane Database Syst Rev. 2011;7:CD009217.

34. Taylor RS, Ashton KE, Moxham T, Hooper L, Ebrahim S. Reduced dietary salt for the prevention of cardiovascular disease: a metaanalysis of randomized controlled trials (Cochrane Review). Am J Hypertens. 2011; 24:843-53.

35. Paterna S, Gaspare P, Fasullo S, Sarullo FM, Di Pasquale P. Normal-sodium diet compared with low-sodium diet in compensated congestive heart failure: is sodium an old enemy or a new friend? Clin Sci (Lond). 2008 114:221-30.

36. He FJ, MacGregor GA. Salt reduction lowers cardiovascular risk: meta-analysis of outcome trials. Lancet. 2011;378:380-2.

37. Graudal NA, Hubeck-Graudal T, Jurgens G. Effects of low sodium diet versus high sodium diet on blood pressure, renin, aldosterone, catecholamines, cholesterol, and triglyceride. Cochrane Database Syst Rev. 2011:11: CD004022.

38. Beckmann SL, Os I, Kjeldsen SE, Eide IK, Westheim AS, Hjermann I. Effect of dietary counselling on blood pressure and arterial plasma catecholamines in primary hypertension. Am J Hypertens. 1995;8:704-11.

39. The ALLHAT Officers and Coordinators for the ALLHAT Collaborative Research Group Major outcomes in high-risk hypertensive patients randomized to angiotensin-converting enzyme inhibitor or calcium channel blocker vs diuretic: The Antihypertensive and Lipid-Lowering Treatment to Prevent Heart Attack Trial (ALLHAT). JAMA. 2002; 288:2981-97.

40. Selmer RM, Kristiansen IS, Haglerod A, GraffIversen S, Larsen HK, Meyer HE, et al. Cost and health consequences of reducing the population intake of salt. J Epidemiol Community Health. 2000;54:697-702.

41. Joffres MR, Campbell NR, Manns B, Tu K. Estimate of the benefits of a population-based reduction in dietary sodium additives on hy- pertension and its related health care costs in Canada. Can J Cardiol. 2007:23:437-43.

42. Asaria P, Chisholm D, Mathers C, Ezzati M, Beaglehole R. Chronic disease prevention: health effects and financial costs of strategies to reduce salt intake and control tobacco use. Lancet. 2007;370:2044-53.

43. Murray CJ, Lauer JA, Hutubessy RC, Niessen L, Tomijima N, Rodgers A, et al. Effectiveness and costs of interventions to lower systolic blood pressure and cholesterol: a global and regional analysis on reduction of cardiovascular-disease risk. Lancet. 2003:361:717-25.

44. Bibbins-Domingo K, Chertow GM, Coxson PG, Moran A, Lightwood JM, Pletcher MJ, et al. Projected effect of dietary salt reductions on future cardiovascular disease. N Engl J Med. 2010;362:590-9.

45. Palar K, Sturm R. Potential societal savings from reduced sodium consumption in the U.S. adult population. Am J Health Promot. 2009;24:49-57.

46. Smith-Spangler CM, Juusola JL, Enns EA, Owens DK, Garber AM. Population strategies to decrease sodium intake and the burden of cardiovascular disease: a cost-effectiveness analysis. Ann Intern Med. 2010;152:481-7.

47. Department of Health. Assessment of dietary sodium levels among adults (aged 19-64) in England, 2011. London: Department of Health; 2012. Available from: http://transparency. dh.gov.uk/2012/06/21/sodium-levelsamong-adults/ Accessed 25 June 2012.

48. National Institute for Health and Clinical Excellence. Prevention of cardiovascular disease at the population level. NICE: London 2010. Available from: http://guidance.nice. org.uk/PH25 Accessed 30 October 2012.

49. Rubinstein A, Colantonio L, Bardach A, Caporale J, Martí SG, Kopitowski K, et al. Estimation of the burden of cardiovascular disease attributable to modifiable risk factors and cost-effectiveness analysis of preventative interventions to reduce this burden in Argentina. BMC Public Health. 2010;10:627.

50. James WP, Ralph A, Sanchez-Castillo CP. The dominance of salt in manufactured food in the sodium intake of affluent societies. Lancet. 1987;1:426-9.

51. Karppanen H, Mervaala E. Sodium intake and hypertension. Prog Cardiovasc Dis. 2006;49: 59-75.

52. Larsson SC, Virtanen MJ, Mars M, Männistö S, Pietinen P, Albanes D, et al. Magnesium, calcium, potassium, and sodium intakes and risk of stroke in male smokers. Arch Intern Med. 2008;168:459-65.

53. Laatikainen T, Pietinen P, Valsta L, Sundvall J, Reinivuo H, Tuomilehto J. Sodium in the Finnish diet: 20-year trends in urinary sodium excretion among the adult population. Eur Clin Nutr. 2006;60:965-70.

54. Consensus Action on Salt and Health. Available from: www.actiononsalt.org.uk/ Accessed 23 July 2012.

55. Food Standards Agency. Agency publishes 2012 salt reduction targets. London: FSA 2009. Available from: www.food.gov.uk/ news/newsarchive/2009/may/salttargets Accessed 28 May 2010.

56. World Action on Salt and Health. Press release-medicalexpertslaunchglobalcampaign against salt to prevent over 2.5 million deaths worldwide each year. London: WASH; 2006. 
Available from: http://www.worldaction onsalt.com/news/saltnews/2007/60497.html Accessed 30 October 2012.

57. Center for Science in the Public Interest. CSPI sues FDA to force end to 20-year delay in regulating salt. Washington, D.C.: CSPI; 2005. Available from: www.cspinet.org/ new/200502242.html Accessed 28 May 2010.

58. Dickinson BD, Havas S. Reducing the population burden of cardiovascular disease by reducing sodium intake: a report of the Council on Science and Public Health. Arch Intern Med. 2007;167:1460-8.

59. New York City Department of Health and Mental Hygiene. Cutting salt, improving health. New York: Department of Health and Mental Hygiene; 2010. Available from: www. nyc.gov/html/doh/html/cardio/cardio-saltinitiative.shtml Accessed 28 May 2010.
60. Mohan S, Campbell NR. Salt and high blood pressure. Clin Sci (Lond). 2009;117:1-11.

61. World Action on Salt and Health. South Africa leads the world in setting salt reduction targets. London: WASH; 2011. Available from: http:/ /www.worldactiononsalt.com/ news/saltnews/2011/60314.html Accessed 18 September 2012.

62. Anderson CA, Appel LJ, Okuda N, Brown IJ, Chan Q, Zhao L, et al. Dietary sources of sodium in China, Japan, the United Kingdom, and the United States, women and men aged 40 to 59 years: the INTERMAP study. J Am Diet Assoc. 2010;110:736-45.

63. Chang HY, Hu YW, Yue CS, Wen YW, Yeh WT, Hsu LS, et al. Effect of potassiumenriched salt on cardiovascular mortality and medical expenses of elderly men. Am J Clin Nutr. 2006;83:1289-96.
64. China Salt Substitute Study Collaborative Group. Salt substitution: a low-cost strategy for blood pressure control among rural Chinese. A randomized, controlled trial. J Hypertens. 2007;25:2011-8.

65. Food Standards Agency. Traffic light labelling, Signposting. London: FSA; 2010. Available from: www.food.gov.uk/foodlabelling/ signposting/ Accessed 28 May 2010.

Manuscript received on 13 June 2012. Revised version accepted for publication on 22 October 2012.

RESUMEN Hay datos probatorios irrefutables de que la ingesta de sal alimentaria es la principal causa de hipertensión y de que una reducción del consumo de sal, del nivel actual de aproximadamente 9 a $12 \mathrm{~g} / \mathrm{d}$ en la mayor parte de los países al nivel recomendado

Reducción del consumo de sal para prevenir la hipertensión y las enfermedades cardiovasculares de menos de $5 \mathrm{~g} / \mathrm{d}$, disminuye la presión arterial. Una reducción adicional hasta 3 a $4 \mathrm{~g} / \mathrm{d}$ tiene un mayor efecto y es necesario seguir teniendo en cuenta la posibilidad de metas de consumo de sal inferiores en la población. Los estudios de cohortes y los ensayos clínicos han demostrado que el menor consumo de sal se asocia con una reducción del riesgo de padecer enfermedades cardiovasculares. La reducción de sal es una de las medidas más rentables para mejorar la salud pública a escala mundial. En la Región de las Américas, hay una alta prevalencia de un consumo de sal superior a $9 \mathrm{~g} / \mathrm{d}$. Las fuentes de sal en el régimen alimentario varían enormemente en los diferentes países; en los países desarrollados, $75 \%$ de la sal procede de los alimentos procesados, mientras que en los países en desarrollo, como algunas zonas del Brasil, $70 \%$ de la sal se añade durante la cocción o en la mesa. Para reducir el consumo poblacional de sal en los países desarrollados, la industria alimentaria debe aplicar una reducción gradual y sostenida de la cantidad de sal añadida a los alimentos. En los países en desarrollo, las campañas de salud pública desempeñan un papel más importante al alentar a los consumidores a consumir menos sal, junto a un reemplazo generalizado de la sal por sustitutos con bajo contenido en sodio y alto contenido en potasio. Numerosos países de la Región de las Américas han iniciado programas de reducción de la sal. El reto actualmente consiste en involucrar a otros países. Una reducción del consumo de sal en la población dará lugar a una mejora importante de la salud pública además de una notable reducción de los costos relacionados con la salud.

Palabras clave Cloruro de sodio dietético; presión arterial; hipertensión; enfermedades cardiovasculares; Américas. 